\begin{tabular}{|c|l|}
\hline Title & Cracking of Cellulose over Supported Metal Catalysts \\
\hline Author(s) & Dhepe, Paresh L.; Fukuoka, A tsushi \\
\hline Citation & $\begin{array}{l}\text { Catalysis Surveysfrom A sia, 11/4), 186-191 } \\
\text { https://doi.org/L10.1007/310563-007-9033-1 }\end{array}$ \\
\hline Issue Date & 2007-12 \\
\hline Doc URL & http://hdl.handle.net/2115/32317 \\
\hline Rights & The original publication is available at www.springerlink.com. \\
\hline Type & article (author version) \\
\hline File Information & CatSurveyA sia_rev.pdf \\
\hline
\end{tabular}

Instructions for use 


\title{
Cracking of cellulose over supported metal catalysts
}

\author{
Paresh L. Dhepe ${ }^{1,2, * *}$ and Atsushi Fukuoka ${ }^{1, *}$ \\ ${ }^{1}$ Catalysis Research Center, Hokkaido University, Sapporo 001-0021, Japan \\ ${ }^{2}$ CREST, Japan Science and Technology Agency, Kawaguchi 332-0012, Japan
}

*To whom correspondence should be addressed. E-mail: fukuoka@cat.hokudai.ac.jp

**Present address: Inorganic and Catalysis Division, National Chemical Laboratory, Pune 411008, India

Short running title: Cracking of cellulose

\begin{abstract}
Cellulose is cracked over supported $\mathrm{Pt}$ or $\mathrm{Ru}$ catalysts under hydrogenolysis conditions in water to give sorbitol as a main product. Among the catalysts tested, $\mathrm{Pt} / \gamma-\mathrm{Al}_{2} \mathrm{O}_{3}$ gave the highest yield and selectivity, and this catalyst was recyclable in repeated runs. It is proposed that cellulose is hydrolyzed by in situ generated acid sites to form glucose, and glucose is immediately reduced to sorbitol over the metal catalyst.
\end{abstract}

KEY WORDS: cellulose; sorbitol; supported metal catalyst; biomass; bio-refinery

\section{Introduction}

Generation of loads of $\mathrm{CO}_{2}$ and finite reserves are the main factors associated with the utilization of fossil fuels for our mounting need for chemicals [1]. In lieu of the fossil fuels, profusely and cheaply available biomass feedstock could be exploited for the synthesis of fuels and chemicals in the future. Furthermore, use of biomass has a carbon neutral impact on 
the environment as whatever amount of carbon liberated in the production of chemicals is again taken up by plants during their growth.

Biomass has a broad meaning and includes plant materials, animal waste, municipal waste etc. Specifically, carbohydrates such as starch, cellulose and hemicellulose are produced by plants during the photosynthesis process using sunlight energy, water and carbon dioxide. Carbohydrates are the rich source of $\mathrm{C}, \mathrm{H}$ and $\mathrm{O}$ elements, which are basic components of organic compounds. Starch is a main constituent of rice, corn and potato, whereas wood is a made up of cellulose (40-50\%), hemicellulose (20-30\%) and lignin (15-25\%). This gives an idea for plentiful availability of the plant biomass material. According to estimates, 1.8 trillion tons of plant material is grown each year [2].

Both starch and cellulose are polymers of glucose units with a molecular formula $\left(\mathrm{C}_{6} \mathrm{H}_{10} \mathrm{O}_{5}\right)_{n}$ (Figure 1). Starch has a linkage of glucose with $1,4^{\prime}-\alpha-$ (amylase) or 1,6'- $\alpha$ glycosidic bonds (amylopectin), while cellulose has 1,4'- $\beta$-glycosidic bonds. Starch is soluble in hot water, but cellulose is insoluble in water or usual organic solvents. Cellulose is only soluble in ammoniacal copper hydroxide, concentrated aqueous solution of zinc chloride, etc. Starch degradation to chemicals can easily proceed over acids, enzymes and catalysts under relatively mild conditions. In contrast, cellulose is hard to degrade due to its robust crystal structure with extensive intra- and intermolecular hydrogen bonds [2-5]. As a result of this reactivity difference, conversion of starch into chemicals is well studied under the bio-refinery concept (Figure 2) [3,6]. Previously we also reported that solid acids such as sulfonated mesoporous silicas catalyzed starch hydrolysis to form glucose [7], which can be further used in food industry or can act as a raw material for the synthesis of various value-added chemicals such as ethanol, fructose, sorbitol etc. In fact, several industries make use of starch as a raw material to produce fuels and chemicals, but it is believed that its main use as food should be secured preferentially. Considering this, inedible cellulose has a great potential as a 
raw material of fuels and chemicals. However, the use of cellulose has been limited to textile, paper, plastic and lumber industries, and still vast amount of cellulose is left to decay. In an effort to utilize this enormous resource, commercial possibility of production of bioethanol from cellulose has been demonstrated by Iogen using enzymatic methods [8]. In conjunction with the importance of this topic, herein we describe the developments occurring in the field of catalytic conversion of cellulose into chemicals and look into the vastly studied aspects of controlling factors for cellulose hydrolysis. The main aim behind this paper is to expedite interest in this field for the future studies.

Figure 1

Figure 2

\section{Cellulose chemistry}

For the efficient conversion of cellulose, it is important to separate cellulose from lignocellulosic materials such as hemicellulose (xylans, mannans, galactans) and lignin (phenolic polymer). This can be achieved by applying steaming, mild oxidation and dilute alkali treatments to the lignocellulosic materials [2]. Since the early 1900's, acid catalyzed, thermochemical or enzymatic methods have been known for cellulose degradation. Most of the studies have been done on cellulose substrates such as Avicel, acid-treated cellulose, microcrystalline bacterial cellulose and so on. Avicel is microcrystalline cellulose prepared from wood by partial hydrolysis, washing and spray drying of pulp [4]. Synthesis of microcrystalline bacterial cellulose is achieved by removing amorphous part from bacterial cellulose with acid treatment.

Dilute sulfuric acid $(<1 \%)$ based Scholler process for the hydrolysis of cellulose to glucose was first industrialized during WWI because of scarcity of fuels [2,9]. In this process, glucose is formed via cellulose-acid complex with swollen cellulose. However, now handful of 
industries run this process due to difficulty in inhibiting further reactions of glucose, corrosion hazards, handling of dangerous acids and generation of large amount of neutralization waste.

Another way to convert cellulose is based on applying high temperature, thermochemical treatment. The process is divided into two categories: gasification and pyrolysis. In the former process, cellulose is decomposed in the presence of small amount of oxygen to give syngas $\left(\mathrm{CO}+\mathrm{H}_{2}\right)$ mixture [2,10]. Conversely, in the latter process cellulose decomposition is accomplished in the absence of oxygen to yield a blend of products such as oils, tar and char [2,11]. The major disadvantage of these processes is lack of selective formation of any compound.

Besides the above methods cellulose degradation can also be performed by enzymes $[2,4,12]$. Cellulase is a complex of three enzymes: endoglucanase, exoglucanase and $\beta$ glucosidase, and these catalyze the dissociation of intermolecular hydrogen bonds, the partial hydrolysis of cellulose to cellobiose or cellotetrose and the complete hydrolysis to glucose. The processes include various steps such as transfer and adsorption of the enzymes onto cellulose surface to form complex, hydrolysis of cellulose and lastly desorption of cellodextrins, glucose and cellobiose from cellulose surface to water phase for further hydrolysis. Although much work has been done, this process has obvious drawbacks of high cost and low activity of enzymes that hamper cost efficiency and difficulty in product-enzyme separation.

Other method developed recently is based on the utilization of sub- and supercritical water. At $320^{\circ} \mathrm{C}$ and $22 \mathrm{MPa}$, cellulose is subjected to the water for a short period of time to form glucose and many other products $[13,14]$. Once again, lack of selectivity for any product and requirement of high energy input restrict its use. Therefore, in order to achieve efficient cellulose degradation by overcoming above mentioned drawbacks, we arrive at a conclusion that development of a new catalytic pathway is a challenge. 


\section{Catalytic conversion of cellulose}

\subsection{Solid acid catalyzed reaction}

It is known that starch is hydrolyzed into glucose over solid acids such as ion-exchange resins [15] and sulfonated mesoporous silicas [7]. It is also shown that liquid acids can convert cellulose into glucose, and we undertook the study of hydrolysis of cellulose over solid acids [16]. Reactions were carried out in a batch type reactor at $150-250^{\circ} \mathrm{C}$ for $24 \mathrm{~h}$ in water media, and we used Avicel (Merck, microcrystalline) as cellulose. The results for various solid acids are summarized in Figure 3. We observed ca. 4\% of glucose yield over HZSM-5, but the activity was very low and thus the process was not of practical use. Ensuing question was how to develop heterogeneous catalysts with high performances for cellulose conversion.

Figure 3

\subsection{Supported metal catalyzed reaction}

The next issue was whether cellulose conversion over supported metal catalysts was possible or not under the hydrogenolysis conditions. A patent claimed that supported $\mathrm{Ru}$ catalysts degrade starch into sorbitol via glucose formation [17], but we observed no degradation of cellulose under the same reaction conditions as reported in the starch degradation. These results showed us that the cellulose degradation is more difficult than the starch degradation. However, we decided to do more study of the cellulose reaction under the hydrogenolysis conditions with $\mathrm{H}_{2}$ pressure and discovered the catalytic formation of sorbitol at relatively high temperature and pressure (Figure 4). Conversion of soluble disaccharide cellobiose was studied as a model reaction of the cellulose decomposition [18].

Figure 4 
It is evident from Figure 5 that the cellulose conversion into sugar alcohols (sorbitol and mannitol) is catalyzed by supported $\mathrm{Pt}$ or $\mathrm{Ru}$ under $5 \mathrm{MPa}$ of hydrogen at $190^{\circ} \mathrm{C}$ [16]. Specifically, $\mathrm{Pt} / \gamma-\mathrm{Al}_{2} \mathrm{O}_{3}$ catalyst gave $31 \%$ yield of the sugar alcohols (sorbitol $25 \%$ and mannitol 6\%) after $24 \mathrm{~h}$. Mannitol is formed as a by-product in this reaction. However, under the same reaction conditions for cellulose, mannitol was not obtained from sorbitol but obtained from glucose with the same molar ratio (sorbitol/mannitol $=4-5$ ). Therefore, it is presumable that mannitol is formed by epimerization of glucose to mannose and subsequent reduction of mannose to mannitol.

Other catalysts such as Pt/HUSY $(\mathrm{Si} / \mathrm{Al}=40), \mathrm{Pt} / \mathrm{SiO}_{2}-\mathrm{Al}_{2} \mathrm{O}_{3}$ and $\mathrm{Ru} / \mathrm{HUSY}(\mathrm{Si} / \mathrm{Al}=20)$ showed ca. $25 \%$ yield of the sugar alcohols. Screening of various transition metals such as Pd, $\mathrm{Rh}$, Ir and Ni showed lower activity than Pt and $\mathrm{Ru}$. Among many supports, $\gamma-\mathrm{Al}_{2} \mathrm{O}_{3}, \mathrm{HUSY}$ $(\mathrm{Si} / \mathrm{Al}=40), \mathrm{SiO}_{2}-\mathrm{Al}_{2} \mathrm{O}_{3}$ and $\mathrm{HUSY}(\mathrm{Si} / \mathrm{Al}=20)$ gave higher yields than HZSM-5, H $\beta$, HMOR, $\mathrm{SiO}_{2}, \mathrm{FSM}-16, \mathrm{ZrO}_{2}, \mathrm{TiO}_{2}$ and active carbon. This emphasizes the fact that supports play a deciding role in the activity of catalyst, but the acidity of the support is not correlated with the apparent catalytic activity. In order to increase the cellulose conversion, the reactions for $72 \mathrm{~h}$ were carried out but no increase in the yield was observed.

Figure 5

\subsection{Recycling of the supported metal catalyst}

In developing a new catalytic process, it is always essential to check the reproducibility of the activity in repeated runs. After the first reaction, we separated the solid (catalyst and unreacted cellulose) from the reaction solution (water and soluble products) by centrifugation and filtration. Then the separated solid was used for the second reaction with similar charge of cellulose, water and hydrogen. The process was repeated after each reaction up to three runs. Figure 6 pinpoints that the catalyst is recyclable in repeated runs since similar activity was observed, although the yields were lower than those of Figure 5 due to slight change of 
reaction conditions. The separated reaction solution after the first run was used for the reaction by adding only cellulose, but no reaction occurred. This result shows that metal was not leached out in the solution from the support.

Figure 6

\subsection{Proposed mechanism}

It is apparent from the data that metal is required for the cellulose conversion. Therefore, we propose that acid sites essential for the cellulose hydrolysis are generated in situ from the molecular hydrogen charged. Under the reaction conditions $\mathrm{H}_{2}$ might undergo dissociative adsorption on the metal surface, and then the hydrogen species reversibly spills over onto the support surface (Figure 7) [19]. Thus, the acid sites formed on the support first catalyze the hydrolysis of cellulose to glucose, which is followed by the reduction of the hemiacetal group in glucose by hydrogen over metal to form sorbitol. Moreover, the reaction of glucose under the same conditions showed ca. 100\% conversion of glucose. Hence, it is suggested that the hydrolysis of cellulose to glucose is the rate determining step in the cellulose decomposition.

Figure 7

\section{Importance of sugar alcohols}

Industrially glucose hydrogenation over Raney Ni catalyst produces sorbitol [20,21]. Use of sorbitol is shown in Figure 8. Sorbitol is used as a sweetener in diet foods and pharmaceutical tablets because of its low calorie value. Sorbitol is a potential raw material for the synthesis of variety of value-added chemicals such as isosorbide, 1,4-sorbitan, glycols, glycerol, lactic acid and L-sorbose [20]. Isosorbide is used to increase the glass transition point of poly(ethylene terephthalate) which helps to store hot drinks in PET bottles. Propylene glycol used as an antifreeze reagent is presently produced from highly flammable propylene oxide by hydration. L-Sorbose is a precursor to vitamin C [22]. Dumesic and co-workers 
reported that hydrogen for fuel cell can be produced from sorbitol over supported metal catalysts with high selectivity compared with glucose [23]. $\mathrm{C}_{5-6}$ hydrocarbons are also formed from sorbitol [24]. Sorbitol can be fermented to ethanol via dehydrogenation using an enzyme [25]. Thus, sorbitol is selected as one of the 12 top value-added products from biomass in the US DOE report [20].

Figure 8

\section{Factors responsible for the cellulose conversion}

The potential utilization of cellulose for fuels and commodity chemicals has been tremendously increased, which is evident from the growing number of papers and patents published in the last few years. In order to see the larger picture of cellulose chemistry, it is important to understand the properties of cellulose such as crystallinity index $(\mathrm{CrI})$, degree of polymerization (DP) and fraction of reducing ends $\left(\mathrm{F}_{\mathrm{RE}}\right)$ that are vital in the degradation of cellulose.

As described above, cellulose is made up of glucose units linked together in a $1,4^{\prime}-\beta$ fashion with anhydrocellobiose as a repeating unit. Due to parallel alignment of several chains of glucose units, vast network of intra- and inter-molecular hydrogen bonding is possible between hydroxyl groups. Moreover, cellulose exists as sheets of many glucopyranose rings lying in a plane one above another to form a three dimensional particle. The hydrogen bonds between two sheets are also possible and are known as intersheet molecular hydrogen bonds, thus binding all the sheets with each other firmly. This unique structure gives rise to one cellulose microfibril, and several microfibrils are hold together by cement called hemicellulose. The whole of this assembly is covered by lignin. This total aggregation is nothing but a wood with addition of small amount of wax, minerals, etc. 
It is believed that crystallinity is an indicator of the substrate reactivity $[2,4,5]$. It can be calculated from the X-ray diffraction (XRD) or nuclear magnetic resonance spectroscopy (NMR) analysis. The crystallinity index (CrI) based on XRD patterns is $0.5-0.7$ for Avicel, 0.81-0.95 for cotton and 0.5-0.7 for wood pulp. From the above values it is clear that Avicel cellulose has substantial amount (30-50\%) of amorphous cellulose [4,5]. ${ }^{13} \mathrm{C}$ NMR analysis is also helpful to know the CrI that is calculated from the peak area of $\mathrm{C}_{4}$ peaks $[26,27]$. The DP values suggest average number of terminal and internal 1,4'- $\beta$-glycosidic bonds, implying how many glucose units are joined together to form a chain. Three types of DP values can be calculated: number average DP $\left(\mathrm{DP}_{\mathrm{N}}\right)$, weight average $\mathrm{DP}\left(\mathrm{DP}_{\mathrm{W}}\right)$ and viscosity based DP $\left(\mathrm{DP}_{\mathrm{V}}\right) . \mathrm{DP}_{\mathrm{N}}$ is 300 for Avicel, 1000-3000 for cotton and 500-1500 for wood pulp [4]. The third factor responsible for activity is $F_{R E}$ that specifies available percentage of reducing groups $(\mathrm{CHO})$ [4]. In other words it is a number of hemiacetals available for opening up the glucopyranose ring. Typical $F_{R E}$ is 0.33 for Avicel, $0.033-0.1$ for cotton and $0.06-0.2$ for wood pulp.

Even though detailed study on these various factors has been carried out, it is still uncertain which factor is the most important in controlling the reactivity of cellulose. It is difficult for a catalyst to access the internal surface of the rigid structure of cellulose. To observe high substrate activity, physical and chemical pretreatments are enforced to manipulate the properties of cellulose. The pretreatments are designed to reduce the value of CrI and DP and to increase $\mathrm{F}_{\mathrm{RE}}$ value by breaking down the hydrogen bonds. This would enhance the accessibility of cellulose surface to interact with the catalysts.

\section{Conclusions}

We have demonstrated that insoluble cellulose is catalytically converted to soluble sorbitol in water under hydrogenolysis conditions over supported Pt or Ru catalysts. The choice of 
support is important for high product yield, but apparent acidity of the support does not directly corresponds to the catalytic activity. Major future tasks are improvement of cellulose conversion and mechanistic study.

\section{Acknowledgements}

We thank Prof. K. Seki, Ms. M. Watanabe and Mr. K. Kasai for characterization of products and experimental assistance.

\section{References}

1. D. L. Klass, Biomass for Renewable Energy, Fuels, and Chemicals (Academic Press, San Diego, 1998).

2. L. T. Fan, M. M. Gharpuray and Y. -H. Lee, Cellulose Hydrolysis (Springer-Verlag, Berlin, 1987).

3. H. Danner and R. Braun, Chem. Soc.Rev. 28 (1999) 395.

4. Y. P. Zhang and L. R. Lynd, Biotechnol. Bioeng. 88 (2004) 797.

5. H. A. Krässig, Cellulose -Structure, Accessibility and Reactivity (Gordon and Breach Science Pub., Yverdon, 1993).

6. http://www1.eere.energy.gov/biomass/integrated_biorefineries.html

7. P. L. Dhepe, M. Ohashi, S. Inagaki, M. Ichikawa and A. Fukuoka, Catal. Lett. 102 (2005) 163.

8. http://www.iogen.ca/

9. J. F. Saeman, Ind. Eng. Chem. 37 (1945) 43.

10. M. Asadullah, K. Fujimoto and K. Tomishige, Ind. Eng. Chem. Res. 40 (2001) 5894.

11. L. Garcia, M.L. Salvador, J. Arauzo and R. Bilbao, Ind. Eng. Chem. Res. 37 (1998) 3812.

12. M. P. Coughlan, Biores. Tech. 39 (1992) 107. 
13. M. Sasaki, Z. Fang, Y. Fukushima, T. Adschiri and K. Arai, Ind. Eng. Chem. Res. 39 (2000) 2883.

14. T. Sakaki, M. Shibata, T. Sumi and S. Yasuda, Ind. Eng. Chem. Res. 41 (2002) 661.

15. A. Abbadi, K.F. Gotlieb and H. van Bekkum, Starch 50 (1998) 23.

16. A. Fukuoka and P.L. Dhepe, Angew. Chem. Int. Ed. 45 (2006) 5161.

17. P. Jacobs and H. Hinnekens (Synfina-Oleofina), EP0329923 (1989).

18. N. Yan, C. Zhao, C. Luo, P. Dyson, H. Liu and Y. Kou, J. Am. Chem. Soc. 128 (2006) 8714.

19. H. Hattori and T. Shishido, Cata. Surv. Jpn. 1 (1997) 205.

20. T. Werpy and G. Petersen, Top Value Added Chemicals from Biomass. Volume 1: Results of Screening for Potential Candidates from Sugars and Synthesis Gas. (U.S. Department of Energy, Energy Efficiency and Renewable Energy, Battelle), http://eereweb.ee.doe.gov/biomass/pdfs/35523.pdf (2004).

21. P. Gallezot, P. J. Cerino, B. Blanc, G. Flèche and P. Fuertes, J. Catal. 146 (1994) 93.

22. P. D. Wulf, W. Soetaert and E. J. Vandamme, Biotechnol. Bioeng. 69 (2000) 339.

23. G. W. Huber, J. W. Shabaker and J. A. Dumesic, Science 300 (2003) 2075.

24. R. R. Davda and J. A. Dumesic, Chem. Commun. (2004) 36.

25. A. T. Brown and C. E. Patterson, Archs oral Biol., 18 (1973) 127.

26. H. Kono, S. Yunoki, T. Shikano, M. Fujiwara, T. Erata and M. Takai, J. Am. Chem. Soc. $124(2002) 7506$.

27. H. Zhao, J. H. Kwak, Y. Wang, J. A. Franz, J. M. White and J. E. Holladay, Energy \& Fuels 20 (2006) 807. 


\section{Figure captions}

Figure 1. Structural formula of starch (amylopectin) and cellulose.

Figure 2. Bio-refinery concept.

Figure 3. Results of cellulose conversion by solid acids into glucose. Reaction conditions: cellulose $0.16 \mathrm{~g}$, catalyst $0.068 \mathrm{~g}$ and water $20 \mathrm{ml}$ in a $30 \mathrm{ml}$ stainless steel autoclave, $190^{\circ} \mathrm{C}$, $24 \mathrm{~h}$. The yield is based on initial $\mathrm{C}_{6} \mathrm{H}_{10} \mathrm{O}_{5}$ units in cellulose.

Figure 4. Schematic representation for catalytic conversion of cellulose into sorbitol.

Figure 5. Results of cellulose conversion by supported metal catalysts into sugar alcohols. Reaction conditions: cellulose $0.48 \mathrm{~g}$, Pt catalyst $0.21 \mathrm{~g}$ or Ru catalyst $0.11 \mathrm{~g}$, water $60 \mathrm{ml}$ and initial $\mathrm{H}_{2}$ pressure at room temperature $5 \mathrm{MPa}$ in a $100 \mathrm{ml}$ stainless steel autoclave, $190^{\circ} \mathrm{C}, 24$ h. The yield is based on initial $\mathrm{C}_{6} \mathrm{H}_{10} \mathrm{O}_{5}$ units in cellulose.

Figure 6. Recycle experiments over $\mathrm{Pt} / \gamma-\mathrm{Al}_{2} \mathrm{O}_{3}$. Reaction conditions: cellulose $0.16 \mathrm{~g}$, $\mathrm{Pt} / \mathrm{Al}_{2} \mathrm{O}_{3} 0.068 \mathrm{~g}$, water $20 \mathrm{ml}$, initial $\mathrm{H}_{2}$ pressure at room temperature $5 \mathrm{MPa}$ in a $30 \mathrm{ml}$ stainless steel autoclave, $190^{\circ} \mathrm{C}, 24 \mathrm{~h}$.

Figure 7. Proposed mechanism for dissociative adsorption of hydrogen and spillover.

Figure 8. Use of sorbitol as a precursor to fuels and chemicals. 


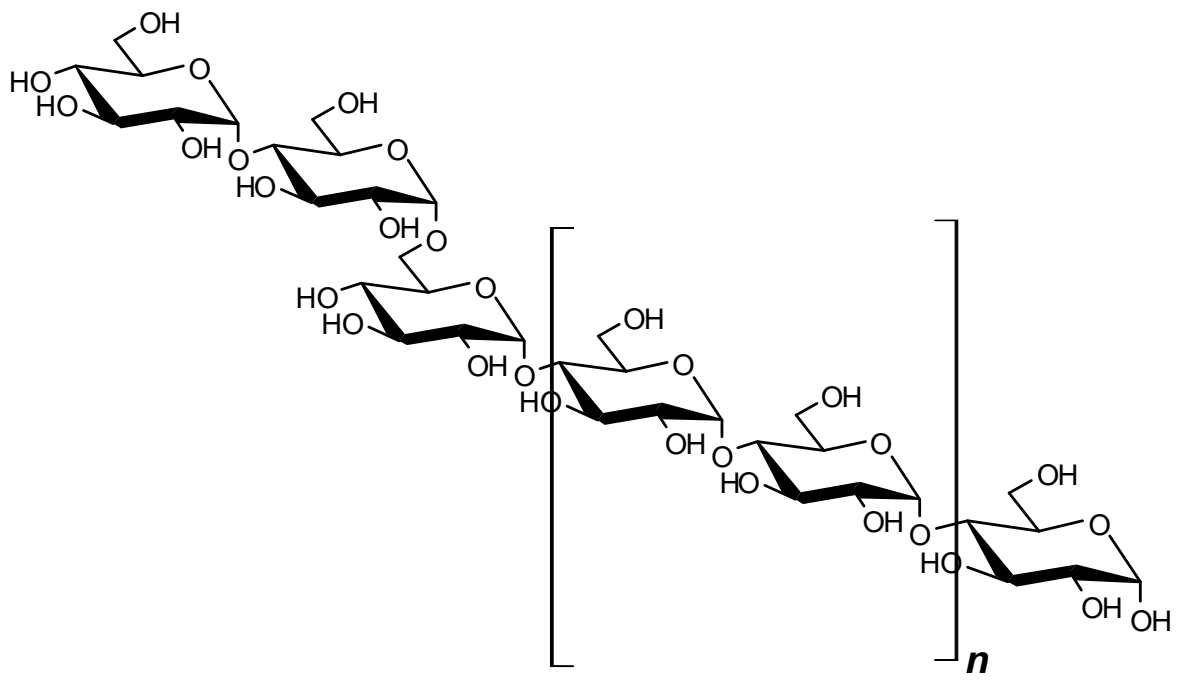

Starch (Amylopectin)

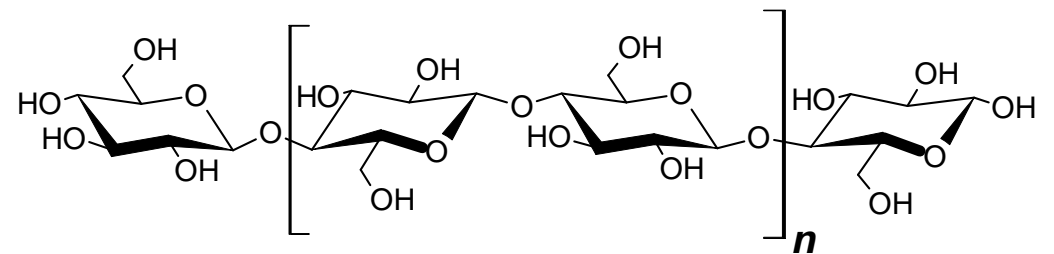

Cellulose

Figure 1. 


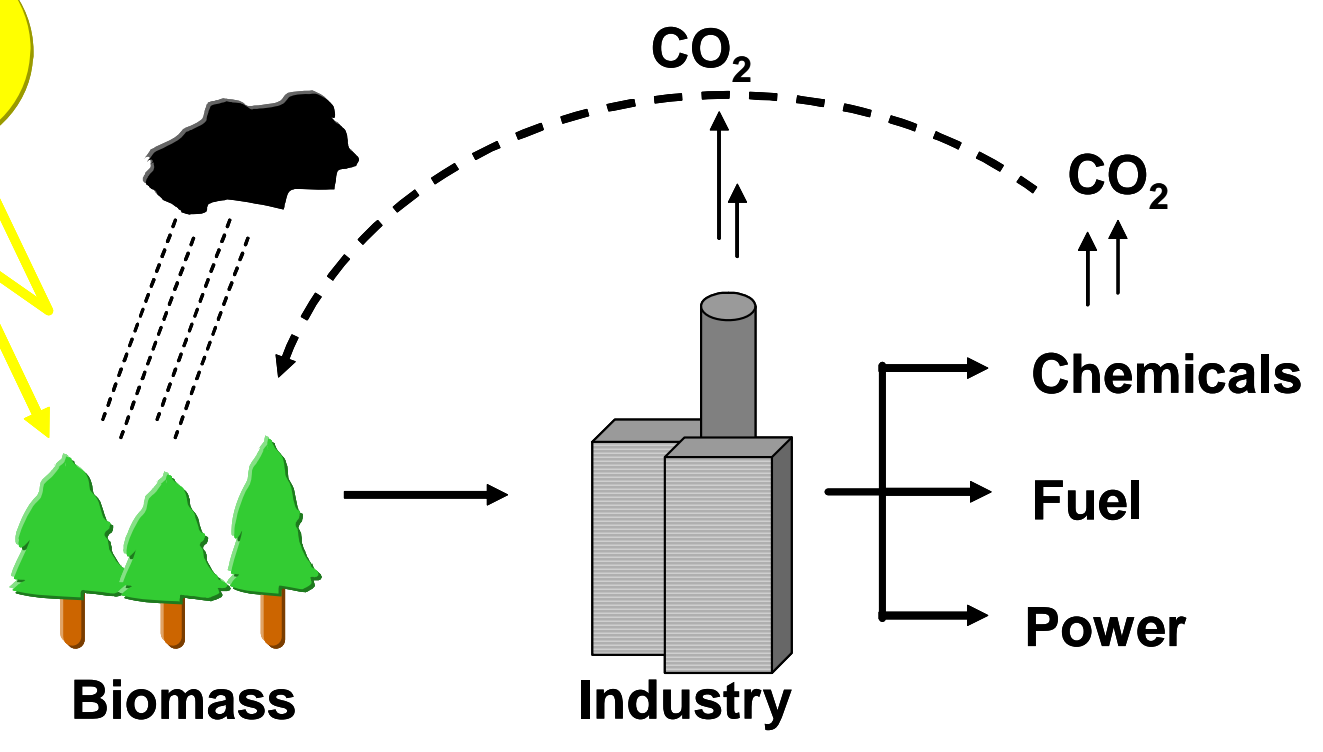

Figure 2. 


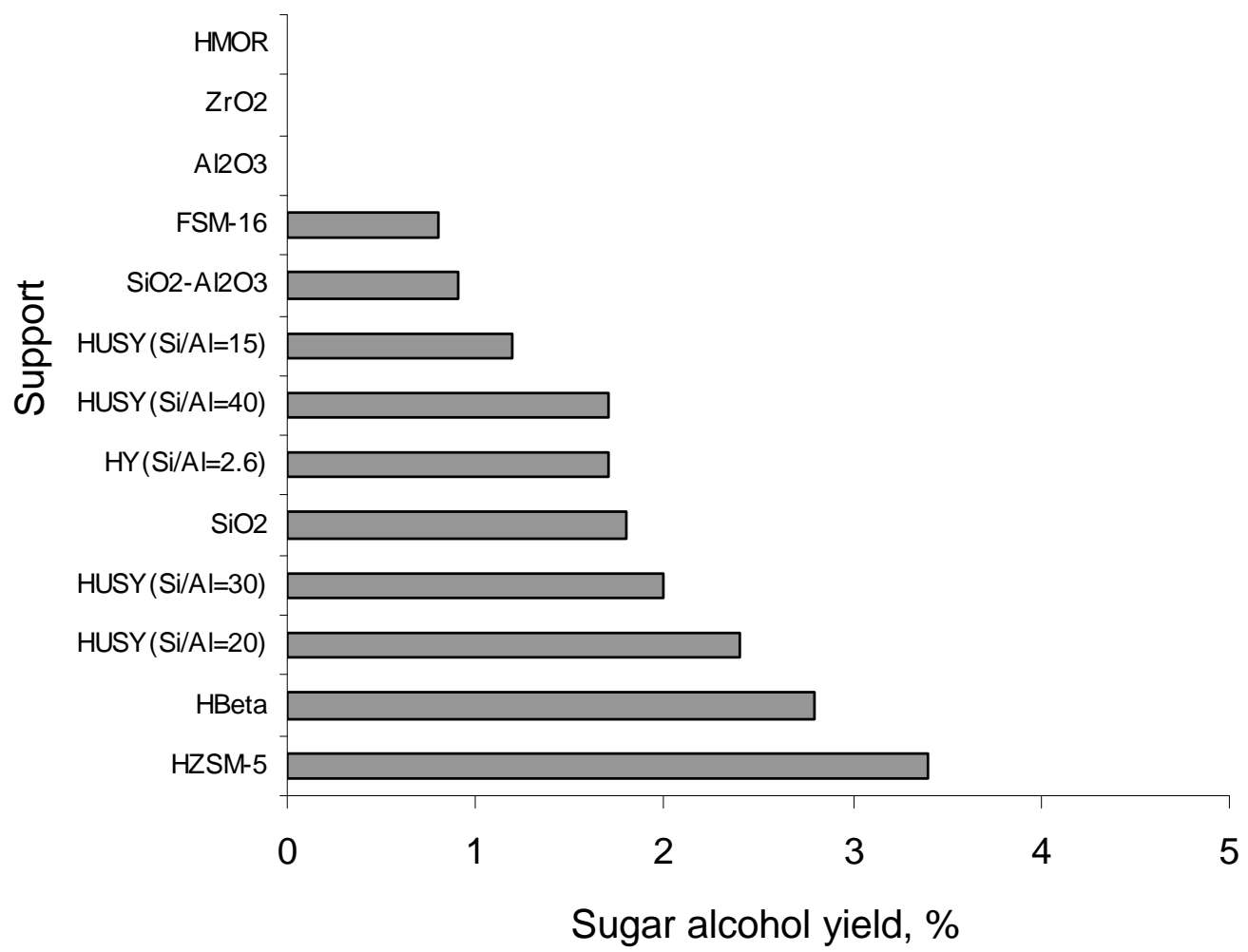

Figure 3. 

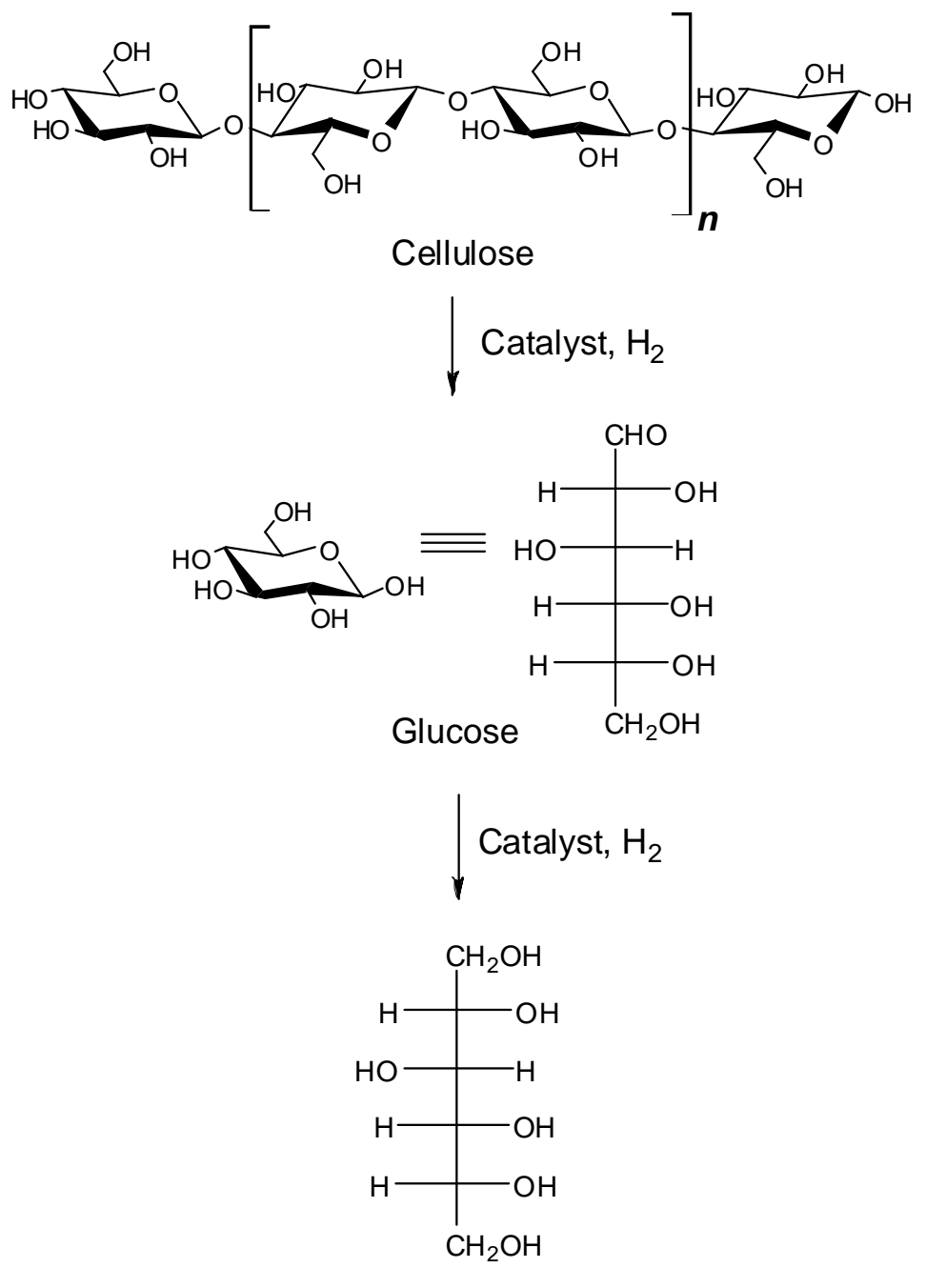

Sorbitol

Figure 4. 


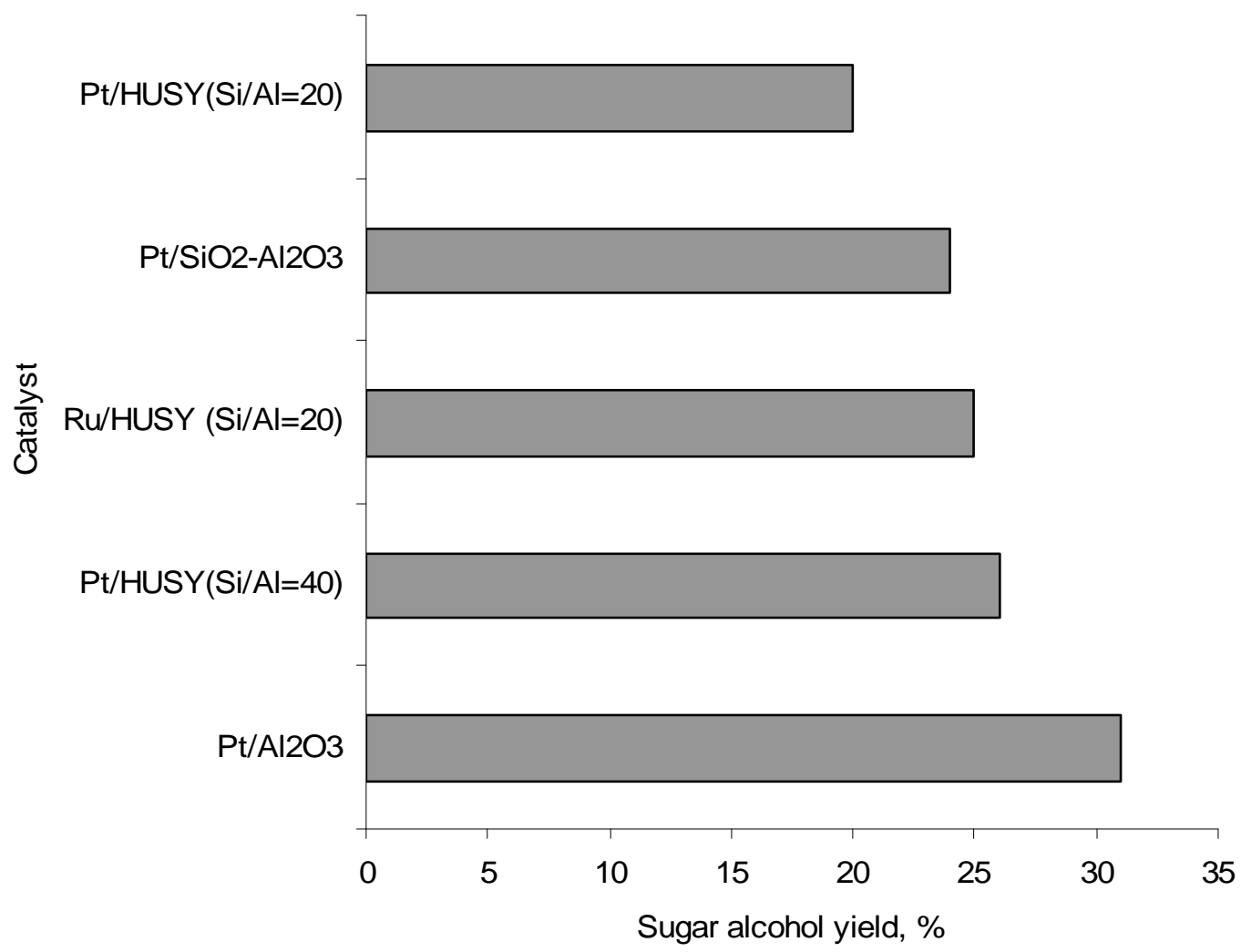

Figure 5. 


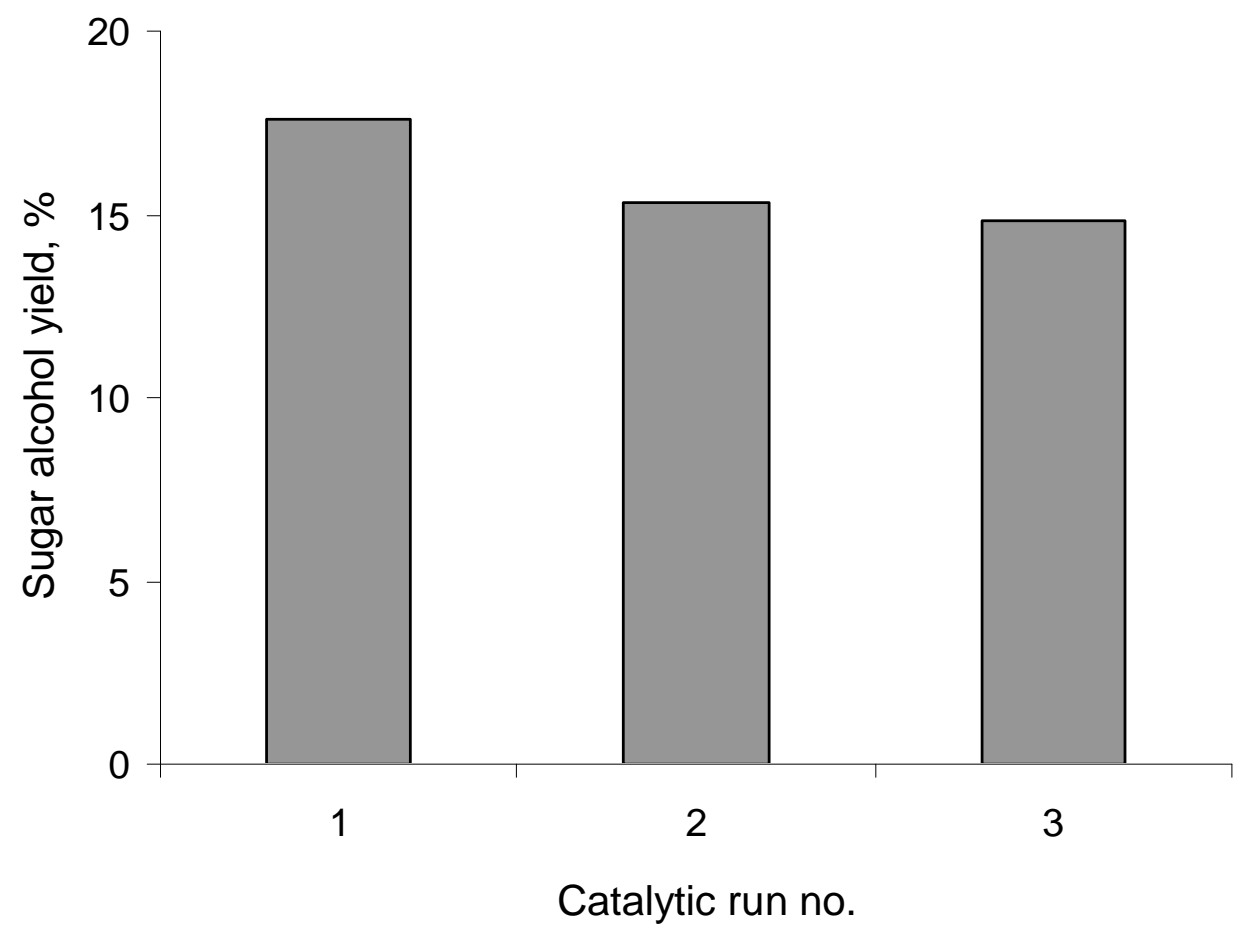

Figure 6. 


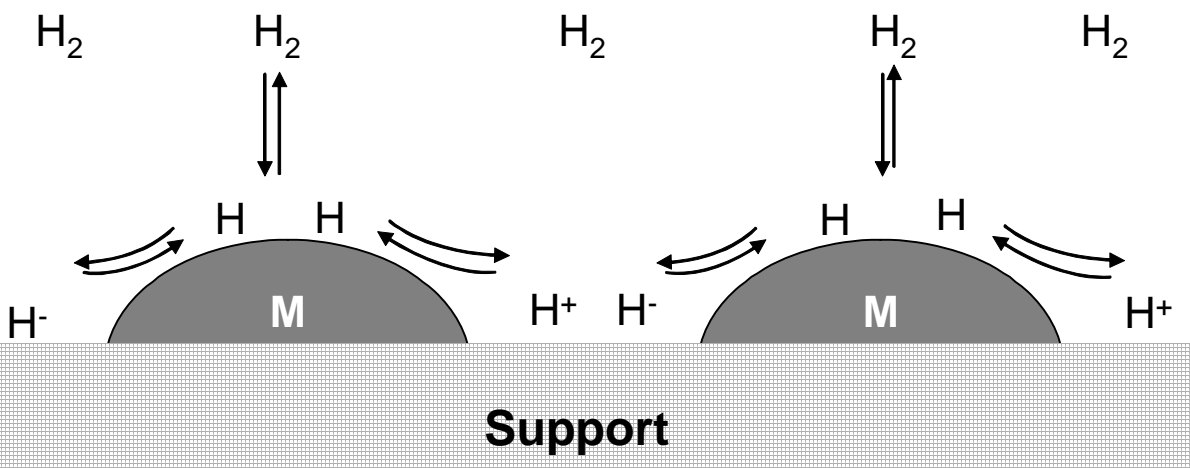

Figure 7. 


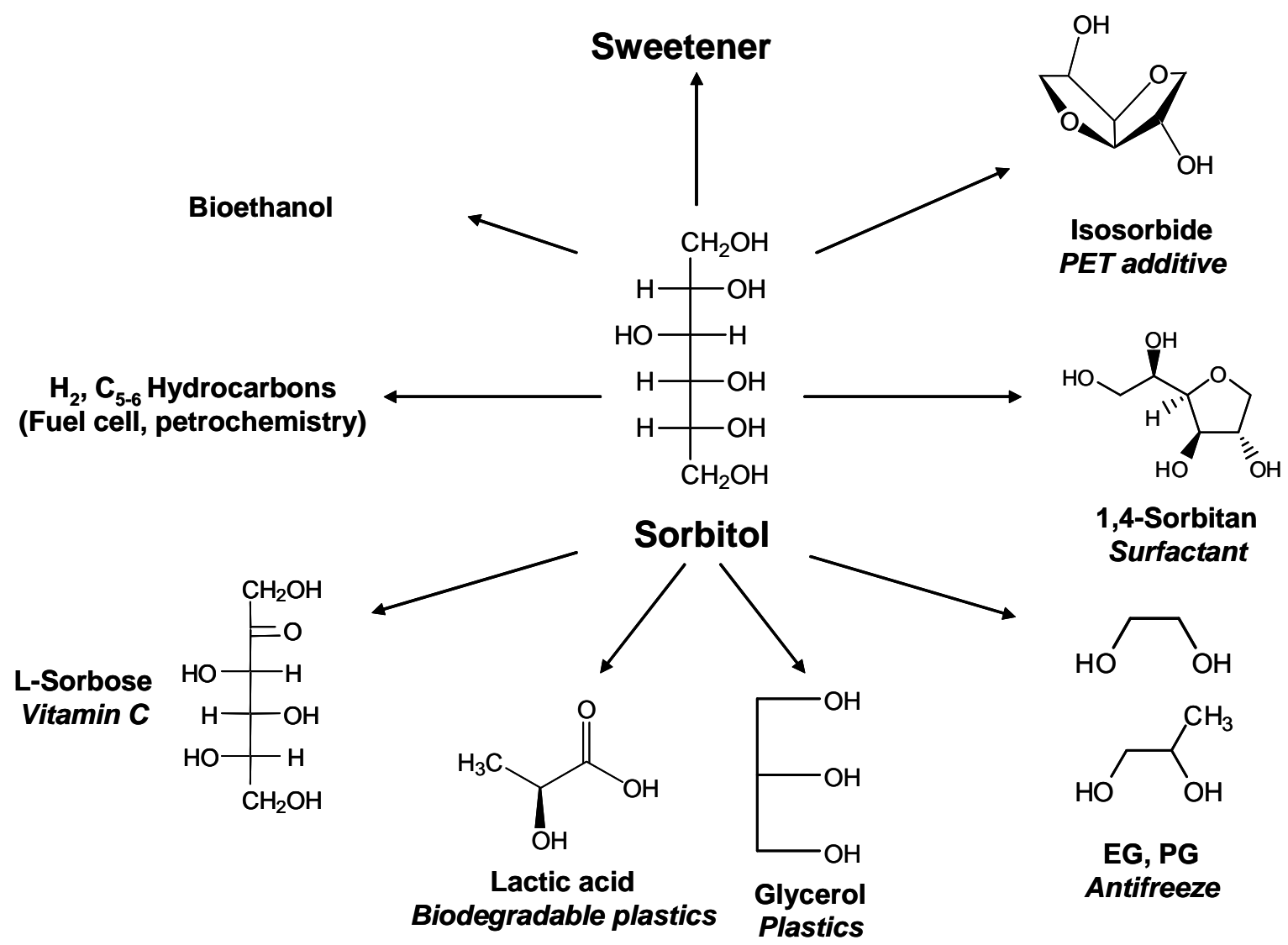

Figure 8 . 